\title{
Why do they choose their instruments?
}

\author{
Irene Martínez Cantero ${ }^{1}$ and Jordi-Angel Jauset-Berrocal ${ }^{2}$ \\ ${ }^{1}$ Music Conservatory of Pilar de la Horadada, C/ Ramon y Cajal, 23, 03190, Pilar de la Horadada \\ (Alicante), Spain \\ ${ }^{2}$ Faculty of Communication and International Relations Blanquerna (University Ramon Llull), \\ Plaça Coromines s/n, 08001 Barcelona
}

irenemc2000@yahoo.com, jordiajb@blanquerna.url.edu

Motivation is a key word in the arts and, especially, in music since it conveys collective, as well as individual, feelings. The beginning of musical instrument learning should be based on the student's musical interest but, due to the casual and improvised nature of everyday situations in which the choice of a musical instrument takes place, tend to underestimate the attention that such interest deserves. This research paper seeks to expound on the lack of knowledge by students as regards musical instruments and on the powerful influence over them by instrumentalists in their environment.

\section{Introduction, justification and current state of affairs}

This article presents a research carried out in the sphere of extracurricular musical lessons on the initial motivation of students for choosing a musical instrument, based on a sample from South-Eastern Spain. The literature consulted on this topic or other related subjects shows similar results, the United Kingdom being the most prominent research centre for such matters (Bera Group, 2004). This convergence could allow for a joint approach to common circumstances in different contexts.

Motivational factors surrounding both music and instrumental learning prove to be significant factors, in spite of curricula and society, which seem to deny them the place they deserve. For a long time now educators have recognised the relevance of motivational elements in the learning process, and systematic attempts have even been devised to identify their characteristics or their relation with interpretative aptitude and accomplishment as regards factors such as interest, home and socioeconomic status; and their contribution to the former elements has been identified (Philips, 1976; Rainbow, Sergeant \& Thatcher, 1974; Wermuth, 1971, in Asmus \& Harrison, 1990).

In this research, specifically, analyses of several variables (age, gender, music studies centre, family of instruments, knowledge of musical instruments, characteristics of the music listened to by the student, favourite musical instrument, instruments in his/her environment, a second musical instrument, family attitude towards musical instrument) have been independently conducted, as well as motivation types (intrinsic, extrinsic due to socio-educational influence, extrinsic through family and peer influence, or extrinsic due to experiences); and relationships are established among the significant results.

\section{Revision of recent related research}

If the review of the literature directly related to the subject matter of this study is materialised, it is appropriate to differentiate between research projects implemented outside of Spain and research projects conducted within the Spanish national context. 
Regarding the first group and in relation to the start of musical education, Hallam (2002) - after an extensive literature review - claims that a high number of Western children take music lessons because the school or family expects them to; while others choose to partake in such learning because music lessons are offered at school and their friends play a musical instrument; and a third subset of students is drawn towards musical education due to the influence of famous musicians or out of the students' own interest in music. The educational institution or its teachers also have an influence, as do the student's individual physical or personality traits. Other influential factors include age (higher in early childhood) or gender (double for girls). Driscoll (2009) detects influence along the same lines for gender, age (especially during transition to secondary school), family and peer groups, and not just at the beginning but also in musical school dropouts.

Likewise, and specifically with regard to musical instrument preference, there are some outstanding studies, such as that carried out by MacKenzie (1991) looking into the reasons that lead to musical instrument learning, where the student's interest and the teacher's encouragement are particularly emphasised. As regards gender differences, they are obvious, especially in relation to socialisation and its potential influence. Likewise, Hallam, Rogers and Creech (2008) conducted a specific analysis on instrument preference. They classify those factors which have an influence on the choice of musical instrument, either as an individual (age, timbre preference, music genres, way of playing, identity symbols in adolescence, gender stereotypes and level of persistence), social (cultural factors, religious elements, stereotype expectations, professionals or teachers' role models, parental influence, peer pressure and siblings' influence) or related to the instrument itself (possibility of access, cost, knowledge of the musical instrument, portability, physical shape, acoustic attributes, tonality, musical instrument family, physical requirements and whether musical repertoire is to be played solo or in a group). According to the authors, the degree of influence from each and all of the aforementioned elements is variable. Yet some aspects are particularly noteworthy: the economic possibility of acquiring the instrument, the family influence, and the stereotyped vision of gender issues (usually already present within the family setting).

It should be noted that all authors mentioned thus far assign great importance to these issues. For Hallam (2002), the reasons that prompt a child to start and carry on playing a musical instrument are not given the prominence they deserve, despite the numerous sacrifices involved in reaching professional proficiency, with individual determination being the best predictor of attitude towards musical practice. In reality when opportunities are limited, children do not get to choose their own musical instrument. They are simply pushed towards one which is readily available (Hallam, Rogers and Creech, 2008). Driscoll (2009) also concluded that children are usually not taken into account as regards this decision.

Moving on to the research carried out in Spain, Valencia, Ventura and Escandell (2003) dealt with musical education dropouts before completing elementary studies, and found that one of the more frequent and decisive reasons reported by teachers and parents is students being unable to choose their own musical instrument. In Lorenzo and Escandell's subsequent assessment (2004), they found again a common reason for dropping out was students playing an instrument which was only their third or fourth choice. Likewise, Cremades, Herrera and Quiles (2011) evaluated motivation at the start of musical training 
in children aged four to eight and concluded that there was significant parental clout - particularly stemming from mothers - as well as influence from siblings, cousins and friends, especially in younger children.

Some studies do not focus on this subject, but address its relation to students' attitude toward the learning situation (Maclntyre et al., 2012) or simply highlight its importance (Bryson, 1997) For example, Asmus and Harrison (1990) concluded that affection for music is the main reason for students to stay musically motivated. Other studies associate student motivation with factors such as musical interest, intrinsic drive, musicality, identity, studiousness, attention, persistence, interpretative success, and acceptance of reviews (Clark, 2002; Proctor, 2002; Sichivitsa, 2003; Atlas, Taggart \& Goodell, 2004; Soboloweska, 2005; Arriaga, 2006; Austin \& Berg, 2006; Francés, 2006; Ghazali, 2006; Lacaille, Gaudreau \& Koestner, 2007; Renwick, 2008; Jarvin \& Subotnik, 2010; Torrico, 2012; Tripiana, 2010; Giráldez, 2012; Schnare, Maclntyre \& Doucette, 2012).

Finally, it is convenient to take into account noteworthy studies emphasising demystification of the talent concept, for their sheer number and importance, and according greater relevance to other aspects, such as motivation and family atmosphere as regards learning (Murphy, 1999; Davidson \& Pitts, 2001; Stollery \& McPhee, 2002; Coulson, 2010). Hence, Murphy (1999) believes that musical thought should be considered as 'intellectual', so the student's ability will hardly acquire any educational value. Davidson and Pitts (2001) show how family influence is essential for the development of talent and aptitude in children. Stollery and McPhee (2002) confer great importance on methodologies based on Gardner's Theory of Multiple Intelligences, which necessarily takes a constructivist approach, where motivation is granted the utmost relevance, whilst talent is pushed into the background. And for Coulson (2010), motivation plays a vital role in shaping musical learning experiences.

\section{Methodology}

\section{Participants and context description}

Research was conducted during school years 2003/04, 2004/05, 2012/13 and 2014/15 in several education centres offering music lessons within their extracurricular activities, in the region of Murcia and the province of Alicante (Bullas, Espinardo, Santa Pola, Pilar de la Horadada, Orihuela, San Pedro del Pinatar), in Spain. Such centres include state-funded as well as private schools, providing both regulated and non-regulated musical studies. The research data was collected at different time periods, with a large margin between two of them, in order to analyse whether, in spite of this gap, the results are maintained.

The study sample consisted of 139 elementary school students (84 girls and 55 boys), aged from eight years, classified into two age subgroups: a) from eight to ten years of age (ten-year-olds included), with a total of 87 students; and b) from 11 to 12 years of age (12-year-olds included), with a total of 52 students. Although these students paid their enrolment fees, a small sample was also taken of students receiving free tuition, for the purpose of analysing any possible differences in the results obtained. 
Table 1. Questionnaire

\begin{tabular}{l}
\hline \hline 1. Which musical instruments do you know? Name them. \\
2. $\quad$ Which is your favourite musical instrument? Why? \\
3. $\quad$ What kind of music do you like? What do you like about the music you listen to? \\
Why? \\
Which musical instrument/s are you studying? Why? \\
6. $\quad$ Do your parents like that musical instrument? \\
Had you listened to that musical instrument before you began playing it? Where? \\
How did it happen? What did you think of the instrument at the time? \\
Hou had the chance, would you study a second musical instrument? Which one? \\
Why? \\
Does anyone from your family or friends study music? Which musical instrument/s \\
do they play? Do you like their instruments? Why?
\end{tabular}

In this geographical area, it is commonplace for music lessons to be extracurricular activities, housed in either formal or non-formal learning centres. For formal learning centres (offering degree courses) a previous selection process of students should be carried out, by asking them to take a several tests. During such testing, musical aptitude is assessed and participants are included in a list ranked according to the scores obtained. Besides, students select several musical instruments. Following the testing order, students finally receive the musical instrument which they may play, from those offered by the centre and requested by students. On the contrary, non-formal music learning schools and academies do not require applicants to take a level test and students are free to choose the musical instrument they wish to learn about.

Attention is also drawn to the existing tradition of musical ensembles or bands, typical of this area, which are characterised by the predominance of wind instruments. The presence of these groups in the events and festivities of each location is part of the cultural environment surrounding the students and their families. In fact, many music centres or schools are created to accommodate these needs. That is why students belonging to these ensembles get their training with more grants or, sometimes, totally free, even for the acquisition of musical instruments.

In order to deepen the results, it was deemed convenient to complement the research by collecting opinions on the issue of musical instrument choice, along with its implications or possible solutions, from a sample of 20 teachers with different instrumental specialities.

\section{Data collection procedure}

Data is collected in written form and encompasses information retrieved from a semistructured interview and a survey, with high predominance of the first type in the same single document (Table 1), since the quantitative questions had the goal of materialising other needs detected in the first project. Questions were answered individually in a total time frame of approximately one hour, although they were arranged in groups of up to 15 students for reading and explaining. Response times for qualitative items varied across 
Table 2. Descriptive variables

\begin{tabular}{llc}
\hline \hline Gender & Female & $60.43 \%$ \\
Age group (years) & Male & $39.69 \%$ \\
& $8-10$ & $62.59 \%$ \\
Education centre & $11-12$ & $33.81 \%$ \\
& Offer initiation courses & $91.68 \%$ \\
Musical instrument family & No offer & $8.32 \%$ \\
& Strings & $74.1 \%$ \\
& Woodwind & $25.9 \%$ \\
& Brass & $2.16 \%$ \\
& Percussion & $1.44 \%$ \\
\hline \hline
\end{tabular}

subjects as needed for each case, but answers to quantitative items were constrained to a previously established time frame of three minutes.

\section{Data analysis}

This is a mixed research project encompassing both qualitative and quantitative methods, though the former is highly preponderant. This qualitative-oriented paradigm was considered to be more adequate since it allowed for a deeper understanding of the analysed factors and the targeted variables. On the other hand, the use of a quantitative methodology provides a higher degree of objectivity to some items which have complemented the general qualitative analysis carried out. The use of both methods, together with the diversity of analysed variables and their potential relations, led to the adoption of Bayesian networks as the analysis method for this study, which entails an innovation with regard to the existing previous research on similar subjects.

A Bayesian network is a multivariate probabilistic model with graphic representation which ties different variables together through causal, relative or absolute dependency relations (Pearl, 2001). Some of its advantages over other models (Heckerman, 1995; Ward, 1998; Gámez, 1998; Huete, 1998; Nadkarni \& Shenoy, 2004; Martínez \& Rodríguez, 2003; Lagnado \& Sloman, 2004; Ruiz, Pérez \& García, 2005; López \& García, 2011) are, inter alia, that: a) it does not need a justification for the initial assumption; b) it facilitates identification of interaction and modeling effects of non-linear relations; c) it allows for an overview of the multivariate probabilistic model for both qualitative and quantitative variants by indicating its most probable status and facilitating its interpretation and the probability assignation or generation; d) it performs bidirectional and abductive inferences; e) it enables operating with lost data, reduction of overfitting, and combination of previous knowledge with experimental data; and $f$ ) it performs local computations and is consequently able to update the model when new information is entered.

\section{Results}

The findings of this research seek to convey to the reader the reasons behind the student's decision to start learning to play a musical instrument as an extracurricular activity. To 
Table 3. Other instrumental preferences and favourite music genre

\begin{tabular}{llr}
\hline \hline Second musical & Strings & \\
instrument family & Woodwind & $59.7 \%$ \\
& Brass & $31.3 \%$ \\
& Percussion & $2 \%$ \\
Favourite musical & Strings & $7 \%$ \\
instrument family & Woodwind & $79.86 \%$ \\
& Brass & $23.74 \%$ \\
Favourite music genre & Percussion & $2.16 \%$ \\
& Related to musical instrument & $2.88 \%$ \\
& Not related to musical instrument & $35.18 \%$ \\
\hline \hline
\end{tabular}

Table 4. Motivations towards study instrument

\begin{tabular}{ll}
\hline Intrinsic motivation & $69.66 \%$ \\
Extrinsic motivation (Family and peer group influence) & $15.83 \%$ \\
Extrinsic motivation (Socio-educational influence) & $11.51 \%$ \\
Extrinsic motivation (Experiential influence) & $3 \%$ \\
\hline \hline
\end{tabular}

this end, several variables were analysed and the most relevant ones were related to motivational factors, in order to gain a better understanding of the overall results and to establish conclusions. This process is handled as it arises from the research itself and the need for further deepening, throughout its whole presentation. Finally, the study is completed with the opinions of the body of teachers. Results are presented in a general, because they were similar throughout all the analysed time periods, across the different educational centres (location, ownership) and also, no differences were detected between free-tuition students and regular students.

Student gender representation is slightly higher for females $(60.43 \%)$. Age group representation is higher for the sample of students aged eight to ten (62.59\%). The vast majority of students attend centres that offer music initiation courses prior to musical instrument instruction (91.68\%). Musical instrument family representation displays a very high prevalence of string instruments $(74.1 \%)$, followed by woodwind instruments $(25.9 \%)$ and a minority of brass $(2.16 \%)$ and percussion $(1.44 \%)$.

The study of a second musical instrument and a favourite musical instrument family runs along similar lines. Representation of the former is: $59.7 \%$ for strings, $31.3 \%$ for woodwind, $2 \%$ for brass and $7 \%$ for percussion instruments. Representation of the latter is: $79.86 \%$ for strings, $23.74 \%$ for woodwind, $2.16 \%$ for brass and $2.88 \%$ for percussion. As regards favourite musical genre, most students listen to music which is not related to their musical instrument $(64.83 \%)$.

As to the reasons given by the students for their choice of musical instrument, most of them are the result of intrinsic motivation (69.66\%), while the remaining $30.34 \%$ mention extrinsic motivation, and they particularly highlight their family and peer group influence $(15.83 \%)$. 
Table 5. Environment and knowledge of musical instruments

\begin{tabular}{llr}
\hline \hline Family attitude towards chosen musical & Positive & $94.6 \%$ \\
instrument & Negative & $5.4 \%$ \\
Musical instruments in the immediate & Same musical instrument & $61.15 \%$ \\
environment & Same musical instrument family & $23.02 \%$ \\
& Different instrument family & $15.83 \%$ \\
Knowledge of musical instruments: & Scarce & $28.62 \%$ \\
Quantity & Medium & $50.08 \%$ \\
& High & $21.3 \%$ \\
Knowledge of musical instruments: & Knows the instruments at the centre & $3.73 \%$ \\
Type & Doesn't know the instruments at the & $96.27 \%$ \\
& centre \\
\hline
\end{tabular}

Table 6. Extrinsic motivation and most relevant variables

\begin{tabular}{llr}
\hline \hline Family attitude & Positive & $86.26 \%$ \\
& Negative & $13.74 \%$ \\
Musical instruments in the immediate & Same musical instrument & $40.30 \%$ \\
environment & Same musical instrument family & $43.53 \%$ \\
& Different musical instrument family & $16.17 \%$ \\
\hline \hline
\end{tabular}

In connection with the high prevalence of family and peer group or socio-educational influence, it is important to take into account the family attitude toward the chosen instrument (positive for $94.6 \%$ of the cases) as well as the musical instruments and their type within one's immediate environment (the same as one's own instrument in $61.15 \%$ of cases, the same musical family as one's own instrument in $23.02 \%$ of the cases, and different to one's own instrument only in $15.83 \%$ of the cases). Likewise, student knowledge of musical instruments can help determine the influence of people within his/her immediate environment, and it has been found that the average knowledge of musical instruments rests on a scarce to medium amount of known instruments (ten instruments) which, in turn, are usually not all the instruments for which lessons are offered at the educational centre for $96.27 \%$ of students. Therefore, such previous knowledge apparently stems from non-formal or informal learning.

Below is the comparison between the most relevant variables of students with intrinsic motivation and others with extrinsic motivation; such variables need greater specificity. This is the case of the family attitude towards the son's chosen instrument and the presence in the student's immediate environment of people studying musical instruments.

Both variables appear to favour the intrinsic motivation of students to choose a musical instrument, since the family appears to have a better attitude $(96.4 \%$ positive for intrinsic motivation, and $86.26 \%$ for extrinsic motivation), and an environment surrounded by fellow instrumentalists playing the same instrument $(60.89 \%$ for intrinsic, and $43.53 \%$ for extrinsic). 
Table 7. Intrinsic motivation and most relevant variables

\begin{tabular}{llr}
\hline \hline Family attitude & Positive & $96.40 \%$ \\
& Negative & $3.60 \%$ \\
Musical instruments in the immediate & Same musical instrument & $60.89 \%$ \\
environment & Same musical instrument family & $25.47 \%$ \\
& Different instrument family & $13.64 \%$ \\
\hline \hline
\end{tabular}

Table 8. Teacher's opinion

\begin{tabular}{llc}
\hline \hline Motivation & Intrinsic & $13.77 \%$ \\
& Extrinsic motivation (Family and peer group influence) & $69.67 \%$ \\
& Extrinsic motivation (Socio-educational influence) & $2.34 \%$ \\
& Extrinsic motivation (Experiential influence) & $0.468 \%$ \\
Prior knowledge & Sufficient & $31.87 \%$ \\
& Insufficient & $68.13 \%$ \\
Importance of choice & Important & $87.72 \%$ \\
& Not Important & $12.28 \%$ \\
& Very frequent & $62.78 \%$ \\
& Fairly frequent & $14.87 \%$ \\
Related to achievement dropout & Sometimes & $19.83 \%$ \\
Reasons that should & Rarely & $2.52 \%$ \\
guide selection & Related & $100 \%$ \\
& Not Related & $0 \%$ \\
& Aptitudes & $29.03 \%$ \\
Parental intervention & Motivation & $68.33 \%$ \\
& Environment & $1.35 \%$ \\
Possible improvements & Pareer opportunities & $1.2 \%$ \\
& Positive as a guide & $73.75 \%$ \\
& Positive as a determination & $0 \%$ \\
& Negative & $26.25 \%$ \\
& Initiation courses and musical instrument tests & $41.4 \%$ \\
& Information and monetary aid & $32.6 \%$ \\
\hline
\end{tabular}

Finally (Table 8 may be consulted for further details), the general profile of the teachers' opinion is presented here: As regards the students, $69.67 \%$ of the teachers believe that the former are externally motivated through the influence of their family or peer group, when it comes to choosing a musical instrument, and $68.13 \%$ of the teachers believe that the students do not possess the necessary prior knowledge. $87.72 \%$ of teachers consider that choosing an instrument is an important matter, and $62.78 \%$ of them believe that this is the main reason for frequent dropouts; $100 \%$ of the teachers consider it is also related to the students' achievement. Among the reasons which should guide the instrument choice, motivation of students is the majority option $(68.33 \%)$, and $73.75 \%$. believe 
parents should intervene for guidance. Finally, as regards the possible improvements of this issue, it declares that the best solution is to organize didactical or school concerts at $41.4 \%)$.

\section{Conclusions and discussion}

All the above and study findings may be summarized as follows:

1. Musical instrument choice is mostly led by intrinsic motivation.

2. When motivation is extrinsic, it is usually due to family and peer group influence.

3. The most demanded orchestral family (first, second or favourite musical instrument) is 'String', followed by 'Woodwind', while 'Brass' and 'Percussion' families are hardly ever mentioned.

4. Students' favourite musical genres do not seem to be related to the instrument they chose.

5. Despite the fact that almost all students attend education centres which offer initiation courses, most of them do not have the appropriate culture or knowledge of musical instruments and they aren't usually aware of all the musical instruments available for studying in their centre.

6. The average student environment favours musical instrument playing: the attitude of families toward the selected musical instrument is eminently positive; besides, the students usually have family members or friends who play the same instrument as them.

7. This environment is better suited for students with intrinsic motivation.

After this summary, the following reflections may contribute to a better understanding of the subject, joining it all together in a unanimous whole, consistent with the current issues of the most recent research projects.

Thus, if the children are not even aware that they may learn to play musical instruments available to them at their own educational centre, along with the strong presence of people playing the same or similar musical instruments in their immediate environment, it is hard to believe that the choice of an instrumental speciality is actually a 'free' decision. Instead, it seems more probable that the influence or knowledge of such environment is what shaped their choice of musical instrument. In any case, it is obvious that families and beginners' courses consider this matter as unimportant, since knowledge of musical instruments is limited to those instruments found within a student's immediate environment. It would, therefore, be worthwhile to rethink this issue in order to find a solution.Another aspect arising from the above relates to the widespread preference for certain instrument families ahead of others. If the student's family and environment play such a decisive role, on the one hand, and preference of a musical instrument family remains constant, on the other, limited knowledge or exposure to certain instrument families with a lower presence in the environment might be at the root of brass and percussion under-representation. Moreover, this would lead to the perpetuation of musical tastes over the years: fewer musicians specialising in certain musical instruments would translate into fewer opportunities for the students to get to know them. 
Knowledge of a musical instrument is one of the reasons for the choice of said instrument or to study music (Hallam, Rogers \& Creech, 2008; Lammont et al., 2003). However, this knowledge is not neutral; it is conditioned by the culture to which the student belongs and develops through the interdependence between individuals and their social environment (Maclntyre, Potter \& Burns, 2012; Boal-Palheiros \& Hargreaves, 2001; Barrett et al., 2011) and is influenced by the appraisal of, bonding to and reactions to music (Shichivitsa, 2003; Schnare, Maclntyre \& Doucette, 2012; Klinedinst, 1991; Arriaga, 2006).

Enculturation and society are intimately tied concepts, and within the scope of previous knowledge, the major importance of informal education must be taken into account, particularly as regards the student's family, for the acquisition of such knowledge (McPherson, 2009; Cremades \& Quiles, 2007) as well as the peer group (Woody, 2005; Cremades \& Quiles, 2007). McEwan (2013) attested to this need in a recent investigation into the sources of academic aspirations for music students at the time of enrolling, by analysing factors such as peer groups and family values, amongst other elements. The relevance of informal education is such that Proctor (2002) points to living in an environment that promotes musical interest as one of the key predictors at the onset of musical instrument learning.

Whereas family and the environment influence one's self-concept and the development of abilities in early childhood and subsequent phases (Gordon, 1990, in Szubertowska, 2005; Austin \& Vispoel, 1998, in Arriaga, 2006; McPherson, 2009; Szubertowska, 2005), in adolescence praise from friends or the media have greater significance (Clark, 2002; Boal-Palheiros \& Hargreaves, 2001). All these factors are currently inducing a reconceptualisation of the term 'motivation' as one of the causes of self, personality and musical sensitivity (Schnare, Maclntyre \& Doucette, 2012; de la Ossa, 2011), whilst maintaining its social and relational aspect (Winn et al., 2007). In essence, subject, context and task interact with each other and determine academic motivation (Tripiana, 2010).

In this sense, it is important to reflect on musical experiences, since they are present in all walks of life, as well as in formal and informal education (Megías \& Rodríguez, 2001; Nebreda, 2000, in Cremades \& Herrera, 2010). The interaction between both types of education should facilitate convergence in most educational situations so as to actively participate in music education (Folkestad, 2006; Green, 2008, in Cremades \& Herrera, 2010).

It follows that, given the implemented research on motivation at the start of the extracurricular activity of music and in the choice of a musical instrument, and after confirming the importance of informal education, and prior musical knowledge in this sample of students, the latter should be the focus of detailed future research. Motivation within the field of music appears to be a factor to be analysed and studied in different contexts, since the consulted literature highlights its relevance for musical instruction continuity. And after this study, research which is exclusively aimed at the relation between the causes underlying the start of music and musical instrument instruction, and its immediate musical environment, reveals an aspect which should not be forgotten. It pools together different results from other research projects which may be justified from this perspective, contributing to the reduction of dropout problems, while making the students feel happier. 


\section{References}

ARRIAGA, C. (2006) Importancia de los condicionantes contextuales en la educación musical. Música y Educación, 19(68), 131-140.

ASMUS, E. \& HARRISON, C. (1990) Characteristics of motivation for music and musical aptitude of undergraduate nonmusic majors. Journal of Research in Music Education, 38(4), 258-268.

ATLAS, G. D., TAGGART, T. \& GOODELL, D. J. (2004) The effects of sensitivity to criticism on motivation and performance in music students. British Journal of Music Education, 21(1), 81-87.

AUSTIN, J. \& VISPOEL, W. P. (1998) How American adolescents interpret success and failure in classroom music: Relationships among attributional beliefs, self-concepts and achievement. Psychology of Music, 26(1), 26-45.

AUSTIN, J. R. \& BERG, M. H. (2006) Exploring music practice among sixth-grade band and orchestra students. Psychology of Music, 34(4), 535-558.

BARRETT, M. S., DUNBAR-HALL, P., MARSH, K., SHEHAN, P., WIGGINS, J., HULTBERG, C., ESPELAND, M., O'NEILL, S., HALLAM, S. \& WELCH, G. (2011). A Cultural Psychology of Music Education. Oxford: Oxford University Press.

BERA GROUP: WELCH, G., HALLAM, S., LAMONT, A., SWANWICK, K., GREEN, L., HENNESSY, S. COX, G., O'NEIL, S. \& FARRELL, G. (2004) Mapping Music Education Research in the UK. Psychology of Music, 32(3), 239-290.

BOAL-PALHEIROS, G. \& HARGREAVES, D. (2001) Listening to music at home and at school. British Journal of Music Education. 18(2),103-118.

BRYSON, B. (1997) What about the univores? Musical dislikes and group-based identity construction among Americans with low levels of education. Poetics, 25(1\&2), 141-156.

CLARK, S. (2002) La motivación. Música y Educación, Revista de revistas, 15(52), 184-186.

COULSON, S. (2010) Getting 'capital' in the music world: Musicians' learning experiences and working lives. British Journal of Music Education, 27(3), 255-270.

CREMADES, R. \& HERRERA, L. (2010) Importancia de la educación formal e informal en la adquisición de conocimientos sobre estilos musicales en estudiantes de conservatorio. Arte y Ciencia: Creación y Responsabilidad, 1\&2(19), 363-382.

CREMADES, R. \& QUILES, O. L. (2007) Familia, música y educación informal. Música y Educación, 20(72), 35-46.

CREMADES, R., HERRERA, L. \& QUILES, O. L. (2011) Las motivaciones de los niños para aprender música en la escuela de música y danza de Melilla. DEDiCA. Revista de Educacao e Humanidades, 1, 293-318.

DAVIDSON, J. W. \& PITTS, S. E. (2001) People have talents: A case study of musical behaviour in an adoptive family. British Journal of Music Education, 18(2), 161-171.

DE LA OSSA, M. A. (2011) Sociología de la música: relación con la educación musical. Música y Educación, 24(87), 18-35.

DRISCOLL, J. (2009) If I play my sax my parents are nice to me: opportunity and motivation in musical instrument and singing tuition. Music Education Research, 11(1), 37-55.

FRANCÉS, R. (2006) La motivación en el aprendizaje musical. Música y Educación, 19(67), 163-164.

GÁMEZ, J. A. (1998). Abducción en modelos gráficos. In J. A. Gámez \& J. M. Puerta (Eds.), Sistemas Expertos Probabilísticos (pp. 79-111). Cuenca: Servicio de Publicaciones de Castilla la Mancha.

GHAZALI, M. G. (2006) Factors influencing Malaysian children's motivation to learn music. PhD thesis. Music \& Music Education, Faculty of Arts \& Social Sciences, University of New South Wales.

GIRÁLDEZ, A. (2012) Éxito y fracaso en la educación musical. Motivación, prácticas y estrategias para el autoaprendizaje musical. Eufonía, 54, 56-61.

HALLAM, S. (2002) Musical motivation: Towards a model synthesising the research. Music Education Research, 4(2), 225-244. 
HALLAM, S., ROGERS, L. \& CREECH, A. (2008) Gender differences in musical instrument choice. International Journal of Music Education, 26(1), 7-19.

HECKERMAN, D. (1995) A tutorial on learning with Bayesian networks At http://research.microsoft.com/ en-us/um/people/heckerman/tutorial.pdf.

HUETE, J. F. (1998) Sistemas expertos probabilísticos: Modelos gráficos. In J. A. Gámez \& J. M. Puerta (Eds), Sistemas Expertos Probabilísticos (pp. 1-40). Cuenca: Servicio de Publicaciones de Castilla la Mancha.

JARVIN, L. \& SUBOTNIK, R. (2010) Wisdom from conservatory faculty: Insights on success in classical music performance. Roeper Review, 32(2), 78-87.

KLINEDINST, R. E. (1991). Predicting performance achievement and retention of fifth-grade instrumental students. Journal of Research in Music Education, 39(3), 225-238.

LACAILLE, N., GAUDREAU, P. \& KOESTNER, R. ( 2007). Political support for self-determination, wealth, and national subjective well-being. Motivation \& Emotion, 31, 188-194.

LAGNADO, D. A. \& SLOMAN, S. (2004). The advantage of timely intervention. Journal of Experimental Psychology: Learning, Memory, and Cognition, 30(4), 856-876.

LAMMONT, A., HARGREAVES, D., MARSHALL, N. \& TARRANT, M. (2003) Young people's music in and out of school. British Journal of Music Education, 20(3), 229-241.

LÓPEZ, J. \& GARCíA, J. (2011). Utilidad de las Redes Bayesianas en Psicología. Almería: Editorial de la Universidad de Almería.

LORENZO, S. \& ESCANDELL, M. O. (2004) El abandono de los estudios musicales en el conservatorio: La opinión de los profesores del centro. Eufonía. Didáctica de la Música, 31, 74-94.

MACINTYRE, P., POTTER, G. \& BURNS, J. (2012) The socio-educational model of music motivation. Journal of Research in Music Education, 60(2), 129-144.

MACKENZIE, C. (1991) Starting to learn to play a musical instrument: a study of boys' and girls' motivational criteria. British Journal of Music Education, 8(1), 15-20.

MARTíNEZ, I. \& RODRÍGUEZ, C. (2003). Modelos gráficos. In Y del Águila et al. Técnicas Estadísticas Aplicadas al Análisis de Datos (pp. 217-257). Almería: Editorial de la Universidad de Almería.

MCPHERSON, G. (2009) The role of parents in children's musical development. Psychology of Music, 37(1), 91-110.

MCEWAN, R. (2013) Secondary student motivation to participate in a year 9 Australian elective classroom music curriculum. British Journal of Music Education, 30(1), 103-124.

MURPHY, C. H. (1999) How far do tests of musical ability shed light on the nature of musical intelligence? British Journal of Music Education, 16(1), 39-50.

NADKARNI, S. \& SHENOY, P. P. (2004) A causal mapping approach to con-structing Bayesian networks. Decision Support Systems, 38(2), 259-281.

PEARL, J. (2001) Bayesianism and causality, or, why I am only a half-Bayesian. Foundations of Bayesianism, Kluwer Applied Logic Series, Kluwer Academic Publisher, 24, 19-36.

PROCTOR, E. (2002). ¿Están preparados? Música y Educación, 15(51), 157-158.

RENWICK, J.M. (2008). Because I love playing my instrument: Young musicians' internalised motivation and self-regulated practising behaviour. PhD thesis. Media \& Performing Arts, Faculty of Arts \& Social Sciences, University of New South Wales University.

RUIZ, F., PÉREZ, A. \& GARCíA, M. E. (2005). Estilos de Vida en Ciudad de la Habana. Hábitos FísicoDeportivos y de Salud. Madrid: Gymnos.

SCHNARE, B., MACINTYRE, P. \& DOUCETTE, J. (2012) Possibles selves as a source of motivation for musicians. Psychology of Music, 40(1), 94-111.

SICHIVITSA, V. (2003) College choir members' motivation to persist in music: Application of the Tinto Model. Journal of Research in Music Education, 51(4), 330-341.

SOBOLOWESKA, S. (2005) Los deberes ¿qué deberes? Música y Educación, 18(64), 195-196. 
STOLLERY, P. \& MCPHEE, A. (2002) Some perspectives on musical gift and musical intelligence. British Journal of Music Education, 19(1), 89-102.

SZUBERTOWSKA, E. (2005) Education and the music culture of Polish adolescents. Psychology of Music, 33(3), 317-330.

TORRICO, R. (2012) Niños musicales: Autodidactas del siglo XXI. Música y Educación, 25(90), 16-28.

TRIPIANA, S. (2010) Despertar el deseo de aprender durante el estudio individual. Música y Educación, 23(83), 32-39.

VALENCIA, D., VENTURA, R. \& ESCANDELL, B. (2003) El abandono de los estudios musicales del grado elemental en el Conservatorio Superior de Música de Las Palmas de Gran Canaria. Anuario de Filosofía, Psicología y Sociología, 6, 77-100.

WARD, W. (1998) Hailfinder: Tools for and experiences with Bayesian normative modeling. American Psychologist, 53(4), 416-428.

WINN, S., HARLEY, D., WILCOX, P. \& PEMBERTON, S. (2007) Reconceptualizing student motivation: Accounting for the social context beyond the classroom. Learning \& Teaching in the Social Sciences, 3(2), 77-94.

WOODY, R. (2005) Qué ha servido de motivación a los músicos expertos. Música y Educación, 18(61), 208-210.

Irene Martínez Cantero has a Higher Degree in Violin and Chamber Music. She is an assistant teacher at University of Alicante; and a professor in the Conservatory of Pilar de la Horadada, the Music School of Orihuela, and other musical centers. She is currently finishing her PhD studies at Autonomous University of Madrid, while simultaneously taking a degree in Primary Education at the University of Murcia, specializing in music. She is a member of Asociación Española de Psicología de la Música e Interpretación Musical (AEPMIM). Her research interests are musical education and the psychology of music.

Jordi-Angel Jauset-Berrocal holds a PhD in Communication, a Masters in Psychobiology and Cognitive Neuroscience, and a Degree in Piano Performance. He is Associate Professor and Researcher in the Faculty of Communication and International Relations at the University Ramon Llull (Barcelona, Spain). He is a member of the Asociación Española de Psicología de la Música e Interpretación Musical (AEPMIM), the International Association for Music and Medicine (IAMM), the European Society for the Cognitive Sciences of Music (ESCOM) and the Society for Music Perception \& Cognition (SMPC). His research interests include the relationship between music and brain; and music's effects in education and health: psychobiological, neural, and behavioral aspects. 